\section{The Operation}

Once the scalp or the patient has been anaesthetized the wound should be opened up fully with retractors and its interior inspected in a good light. Portions of hair, masonry, dust, and other foreign matter are wiped out with wet swabs and the wound freely irrigated with sterile normal saline. As the wound is usually grossly contaminated with pulverized brick, cement, and dust driven in by the blast, actual application of soap and scrubbing-brush will be necessary. Saline alone will not get rid of dirt. The wound should be thoroughly irrigated with normal saline until it is "white." The floor of the wound is now examined for a crack or depressed fracture or hole of entry.

Scalp wounds are apt to be more complicated than they look, and it is not always possible, unless really good radiographs have been taken beforehand, to know with absolute certainty that a fracture will not be found tucked away under a flap of skin. Even when the wound is first held open a fracture may not be seen.

If there is a depression the operator may run into trouble. The withdrawal of a bone fragment may cause an ugly situation in which every technical aid may be required. The easiest cases are those in which the bone has been fragmented and lies loose in the wound-e.g., in a gutter wound. The most dangerous are those in which a piece of bone is tilted edge-on against the sagittal or lateral sinuses. It is not our purpose to speak of the details of treatment in such emergency situations. But it must be affirmed that an excellent surface operation is within the powers of any surgeon with training, and that attention should be focused on the more superficial parts, deep excursions into the brain being avoided.

If no fracture is found after the wound has been thoroughly gone over, floor and sides, all bruised and damaged soft tissue must be removed from the floor, and the contused edges or even clean-cut edges should be excised. This must be done sparingly because the removal of wide ellipses of scalp leaves concave margins that cannot be approximated, so inelastic is the scalp proper. A slice 2 to $3 \mathrm{~mm}$. in thickness is quite adequate. The hindrances to neat excision are two: first, the vascularity of scalp may cause free bleeding that impedes the view; secondly, irregularities and cross-fissures in the wound may pass beyond the line of the intended cut. The first difficulty is got over by the finger-pressure of an assistant exsanguinating the scalp margins until artery clips can be placed on the galea and turned over. A quick worker can do this single-handed. The weight and pull of the forceps on the galea quickly stops the bleeding while the other side is dealt with. As for the cross-fissures, they do not matter if they are well cleaned and thoroughly irrigated with normal saline so that all dirt is removed mechanically, but if a fissure is large it calls for separate deliberate excision. At this stage sulphanilamide, sulphadiazine, or sulphathiazole, or all three, should be freely dusted into the wound. Closure is effected by one row of sutures if the laceration is not excessively large or bleeding too profuse, and in those rarer wounds which do not divide the galea. Fine silk, "fine dermal," and nylon are all satisfactory suture material, though most neurosurgeons have come to prefer silk. Silkworm-gut, unless it is the finest procurable, is bad for the scalp. Closure of a scalp wound with one row of sutures requires that the skin and galea should be included in the stitch and just enough tension used in tying, so that good apposition is obtained and the margins of the wound lie flat. These stitches are put in at intervals of about $1 \mathrm{~cm}$. When necessary more superficial sutures may be placed between them. A soft rubber (Penrose) drain should be brought out of one end of the incision or through a separate stab wound.

When two rows of sutures are used the deeper layer of stitches takes only the galea; they are inserted about $1 \mathrm{~cm}$. apart; after tying, the ends are cut very short-indeed, practically on the knot. Fine silk or fine nylon is the only type of material suitable for this deep layer of sutures. Buried catgut is thoroughly bad, for it leads to trouble. Linen thread and cotton are little better. The general surgeon would do best to use the one-layer closure. Again, it is best to drain such wounds just as if only one row of sutures had been put in.

Following closure with one layer of sutures, and even if two rows have been used, a well-padded and firmly applied head- dressing is required. This, if it produces firm pressure on the scalp wound, will minimize bleeding. Dressings should be changed at the end of 12 to 18 hours-observing the most meticulous technique against droplet and cross-infection-the drain removed, and somewhat less firm dressings applied. Skin stitches may be removed after 3 to 4 days.

\section{Transportation of Cases of Head Injury}

It is commonly objected that head injury cases travel badly ; but recent experience has shown that they travel well (unless very deeply unconscious or moribund) both before and after operation, and it is important that surgeons correct their view on this matter. There is but little truth in the dogma that these patients cannot be moved, and all recent experience supports the opposite view, provided the journey is not of too long duration. Hence certain cases of injury, when recognized for what they are-scalp wounds, complicated by (1) loss of scalp tissue ; (2) fractures of skull, especially those overlying the frontal sinuses; (3) cerebral injury-should at once be moved to a proper centre, where they can be treated and retained. Semi-conscious or unconscious patients should always be nursed, or be transported in the prone or semi-prone position to secure unobstructed breathing and to prevent the inhalation of blood or vomitus.

If through the exigencies of any particular circumstance patients cannot be moved, a thoroughly effective surface operation should be aimed at. Skilful treatment of the superfices leads to primary healing and survival of the patient. Should a deep missile or deeply in-driven fragment require removal later, this can safely be done if the scalp wound is healed. In cases that were admitted to neurosurgical centres with scalp wounds healed or healing and bone fragments embedded in the brain no untoward symptoms developed, though these fragments might have to be removed later.

\section{REFERENCES}

Cairne, H. (1941). British Medical Journal 2, 465.

Hare, R. and Willits, R. E. (1942). Canad. med. Ass. J., 46, 23.

Hawking F. (1941), British Medical Journal, 1, 263.

Hine, M. L (1918), Brit. J. Ophthal., 2, 12.

McKissock. W., and Brownscombe, B. (1941). Lancet, 1, 593.

Miles, Aritish Medical Journal, 2, 855, 895.

Trotter, W., and Wagstaffe, W. W. (1922). Medical Services: Surgery of the War, 2,1 .

\section{SYNCOPAL REACTIONS IN BLOOD DONORS AN INVESTIGATION OF 222 CASES BY}

\author{
G. E. O. WILlIAMS, M.D. \\ Deputy Regional Blood Transfusion Officer
}

The incidence of syncopal reactions in blood donors following donations of blood has attracted the attention of workers in various Blood Transfusion Services, particularly with regard to the possibility of correlating such reactions with certain individual features in the affected donors. An attempt was therefore made to determine by investigation whether the incidence of fainting in blood donors was associated with any constitutional or circumstantial peculiarities in the individuals concerned.

\section{Clinical Features of Vasomotor Reactions}

As it was impossible for the limited number of available medical officers to devote time to the careful examination of each donor, no records of pulse rates, blood pressures, etc., were kept, but the following brief classification of the reactions was made according to their severity: Grade 1: Feeling of faintness only, with or without nausea or vertigo, but with no loss of consciousness and only slight after-effects. Grade 2: Loss of consciousness for a short time, but with no alarming or excessively prolonged after-effects. Grade 3: Prolonged loss of consciousness, or unconsciousness of shorter duration with clonic movements or very severe and prolonged aftereffects. The incidence of these types of reaction is illustrated in Table VI. 


\section{Predisposing Factors}

The general appearance of the donor may be such that the possibility of a reaction can be anticipated. Among features favouring such reactions are the following:

1. The donor is commonly of tall thin build and is obviously ill at ease, attempting to conceal his discomfiture under a cloak of facetiousness or an exaggerated interest in his surroundings, and particularly in his own blood. He often cannot resist the temptation to lean over and watch the blood flowing, but may adopt the opposite extreme of deliberately, and with obvious effort, attempting to direct his attention to something else. Both sexes are about equally represented in this group.

2. Young men or girls who are attending as members of a group of donors from a factory or other place of work usually chatter about the subject of fainting while awaiting their turn, and it is only necessary for one of them to succumb for reactions to follow among the remainder. This type of "epidemic fainting "is almost confined to the youngest age group, and is particularly frequent among members of both sexes serving in the Forces. In our series this must be considered as a potent factor in producing the high figures seen among donors under the age of 30 . Above this age "epidemic fainting" was rare enough to be ignored in the interpretation of results.

3. A rare but definite type of donor who is liable to a severe and sometimes alarming reaction is the middle-aged female with a plethoric complexion and small dilated venules visible over the malar region, but who also shows pale or cyanotic mucous membranes and circumoral pallor. These individuals, of whom we have noted four, denied being otherwise than in their usual health before giving their transfusions, but shortly after concluding their donations they collapsed and rapidly became umconscious. The pulse was slow and of extremely poor volume, the pupils were dilated, the extremities were cold and clammy, and respirations were almost undetectable for a short time. This resembles the picture familiar to many as that of a severe and fatal cardiac or pulmonary catastrophe; but with rest postural treatment, and warm drinks recovery occurred in all our cases.

Of the remainder it can only be stated that as a general impression vasomotor reactions are rare among the bull-necked and stout. This impression was confirmed by our investigation (see Table V).

\section{Symptomatology}

Reactions occur most commonly within the first five minutes after completing the donation. It is rare for the first symptoms to appear within five minutes of the start, and, as most bottles are filled within five to seven minutes, the onset of an attack is seldom observed while the needle is still in the vein. Pallor is the most constant presenting sign, and usually precedes any subjective sensation, save possibly that of warmth. Lowering of the head at this stage may abort the attack. Often, however, there is a slowing of the pulse rate, which, if not detectable when pallor is first noticed, occurs in nearly every case before consciousness is lost, and lasts for the duration of the attack. The pulse rate during this stage is usually between 48 and 60 a minute, and is of full volume at first, becoming weaker as the condition progresses. The pulse also shows the first sign of recovery, for by the time both volume and rate are restored the patient is usually able to sit up without discomfort. Sweating may occur, but this is by no means the rule. Nausea and vomiting have also been recorded, particularly when the donor has recently eaten a rather heavy and indigestible meal. When consciousness is lost clonic movements occasionally occur, and are probably of asphyxial origin. The hysterical type of attack is comparatively rare, and is associated with such familiar symptoms as violence, shouting, hyperpnoea, and occasional vesical incontinence. Such phenomena are occasionally observed in association with minor forms of vasomotor discomfort, the latter sufficing to precipitate the hysterical tendencies of the donor.

\section{Collection and Interpretation of Data}

Between Aug. 19 and Dec. 31, 1941, a questionary was completed on behalf of every donor showing vasomotor reactions after his donation. Besides giving the name, age, and address of the donor and the date on which he was bled, the following information was also included:

1. Name of hospital at which the bleeding took place.

2. Name of the medical officer who was responsible for the bleeding.

3. The severity of the reaction.
4. Previous attendance, if any, and whether accompanied by fainting.

5. The donor's liability to faint on occasions other than when giving transfusions.

6. The time interval since the last meal, and whether this meal was heavy, moderate, or light.

7. The nature of the donor's occupation (whether manual or sedentary), and approximately how many hours a week.

8. A brief description of the donor's appearance-e.g., tall, dark, stout, etc.

9. The incidence of menstruation in female donors.

During the period under review 3,241 donors were bled by a team of experienced medical officers working in four different hospitals, assisted occasionally by resident medical officers of the hospitals concerned. Of these donors 222 suffered from vasomotor disturbances, and the information enumerated above was recorded in each case. As a control, similar details were noted from a random selection of 428 donors who had not shown any such disturbances. It was impossible to extend this investigation to every donor, but the system of sampling on this scale was considered adequate for the present series of observations.

As an illustration of the method employed for calculating the actual number of donors belonging to any particular class or group, the following example may be quoted:

$$
\begin{aligned}
& \text { Total number of donors bled fainted }{ }^{\prime} \quad \ldots \quad 3,241
\end{aligned}
$$

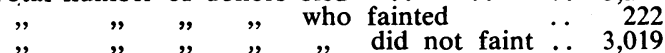

The sample taken of donors who did not faint consists of 428 :

$$
\text { i.e., } \frac{428}{3,019}=\frac{1}{7,054} \text { of the total. }
$$

To calculate the number of males in the 3,241 donors it was therefore necessary to multiply the number of males in the sample by 7.054 and add to this the number of males who fainted. The result obtained in this way was 1,093 .

The actual number of males bled, obtained from the records of bleeding sessions for the period under review, was 1,076. The difference between these two figures, amounting to less than $2 \%$, can be ignored for the purpose of this investigation. Similar calculations are applicable to all groups of donorse.g., ages, menstruation, etc.- and for convenience the results are included in the tables under the heading "Calculated No. of. . . ." in each case where this method has been employed.

The usually accepted criterion of significance of differences in percentages was employed-namely, Difference/Standard Error of Difference. If this quotient exceeds 2 the difference may be accepted as unlikely to be fortuitous, and therefore statistically significant.

\section{Results of Investigations}

Environment.-Table I shows the incidence of reactions at each of the four hospitals in regular use by the Blood Transfusion Service. A considerable difference is noted on comparing the fainting rates at hospitals Nos. 1 and 4 with those at Nos. 2 -and 3 . The following description of the methods employed

TABLE I.-Incidence of Fainting at Each of Four Hospitals used for Collecting Blood

\begin{tabular}{c|c|c|c|c|c|c}
\hline \multirow{2}{*}{ Hospital } & \multicolumn{2}{|c|}{ Males } & \multicolumn{2}{c|}{ Females } & \multicolumn{2}{c}{ Total } \\
\cline { 2 - 7 } & Attended & \% Fainted & Attended & \% Fainted & Attended & $\%$ Fainted \\
\hline 1 & 248 & 4.072 & 593 & 6.408 & 841 & $5 \cdot 683$ \\
2 & 405 & 7.90 & 671 & 8.94 & 1,076 & $8 \cdot 55$ \\
3 & 219 & $6 \cdot 849$ & 462 & $8 \cdot 87$ & 681 & $8 \cdot 223$ \\
4 & 204 & $5 \cdot 382$ & 439 & 3.416 & 643 & 4.043 \\
\hline Total & 1,076 & 6.319 & 2,165 & $7 \cdot 113$ & 3,241 & 6.848 \\
\hline
\end{tabular}

at the four hospitals sug jests possible reasons for this difference :

Hospital 1.-Donors are treated on ward beds and are able to. see each other. They get up almost immediately after giving their blood, but are constantly under the supervision of senior nürses. The medical officer is also able to see each donor frequently. In this way it is possible that many incipient reactions are arrested by early detection and treatment. Donors have not far to walk to receive their cups of tea, and their 
surroundings are, generally speaking, pleasant, well ventilated, and cheerful.

Hospital 2.-The Transfusion Service is here accommodated in an operating theatre and two ante-rooms. Donors lie on trolleys or operating tables which are high, hard, and rather uncomfortable. The general arrangement does not permit of continuous observation by the medical officer. Donors get up immediately and have to walk a considerable distance along an ill-lit passage to receive their tea. It is during this walk and the consumption of tea that most of the reactions are detected.

Hospital 3.-Accommodation here is good; donors cannot see each other, and lie on high couches intended for treatment of shock casualties. The arrangement renders frequent observation of donors by the medical officers impossible, and the nursing staff is not large enough to enable each donor to be under the constant supervision of a senior nurse. After giving his blood there is a long walk ahead of the donor before receiving his cup of tea, and here again most of the casualties occur in the tea-room.

Hospital 4.-This differs from the others in that donors are accommodated in the out-patient cepartment, where they lie on couches in individual partitioned cubicles. The nursing staff is experienced in transfusion routine, as the nurses are not of ten changed from one duty to another. Donors are not allowed to move until they have had their cup of tea and until their arm dressings have been examined and passed by senior nurses. This gives them plenty of time for acclimatization, both before and after giving their blood. Although their supervision by the medical officer is as difficult as in the other hospitals, the extra rest provided more than compensates for this.

Influence of Supervision by Medical Officers.-Examination of the incidence of fainting among donors bled by five medical officers who regularly assist in this work shows a remarkable similarity in results. Each medical officer experiences a rate of between 8 and $11 \%$ of fainting among the donors bled by himself. Donors approximately equal in number to those bled by each of the five regular medical officers were dealt with by resident medical officers, students, and other medical men who were not experienced in this type of work. Their fainting rate showed the strikingly low figure of $3.25 \%$. This can only be explained by the fact that the latter group of medical officers had an individual turnover of only a fraction of the number that could be managed by their more experienced colleagues, and were in charge of only one or two couches at a time. They were therefore constantly in personal touch with each donor. The pronounced difference in their reaction rates compared with those of medical officers with a greater turnover of donors strongly suggests the desirability of continuous supervision of the donor by the doctor.

Incidence of Fainting among Donors of Both Sexes of Different Age Groups.-Comparison of the incidence of fainting in males and females shows a significant increase among males

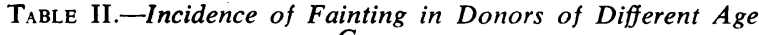
Groups

\begin{tabular}{|c|c|c|c|c|c|c|}
\hline & \multicolumn{2}{|c|}{ Under 30} & \multicolumn{2}{|c|}{ Over 30} & \multirow{2}{*}{$\begin{array}{l}\text { Diff./S.E.E. } \\
\text { of Diff. }\end{array}$} \\
\hline & & $\begin{array}{l}\text { Calculated } \\
\text { No. }\end{array}$ & Fainted & $\begin{array}{l}\text { Calculated } \\
\text { No. }\end{array}$ & Fainted & \\
\hline $\begin{array}{l}\text { Males } \\
\text { Females }\end{array}$ & .. & $\begin{array}{r}312 \\
1,133\end{array}$ & $\begin{array}{c}14 \cdot 1 \\
7.84\end{array}$ & $\begin{array}{r}709 \\
1.065\end{array}$ & $\begin{array}{l}3.52 \\
4.6\end{array}$ & $\begin{array}{l}4.06 \\
3.1\end{array}$ \\
\hline \multicolumn{2}{|c|}{ Diff./S.E. of Diff. . } & \multicolumn{2}{|c|}{$2 \cdot 9$} & \multicolumn{2}{|c|}{$1 \cdot 15$} & " \\
\hline
\end{tabular}

under the age of 30 compared with the fainting rates among females of the same group (Table II). Above the age of 30 there is no such difference between the sexes. A similar difference was found, taking each sex separately, between the incidence of fainting among donors under the age of 30 and that among those above that age. It may be that the high incidence of reactions in the younger males was in part due to the preponderance of this age group among those attending to be bled as members of a group of donors from factories, and particularly from units of the armed Forces, a class of donor which, as mentioned previously, is prone to the "epidemic" type of reaction. This same factor may also have influenced the results obtained from female donors, as most of those attending as members of a group are known to be chiefly of the younger age groups. These findings do not coincide with those of Greenbury (British Medical Journal, 1942, 1, 253), who found the incidence of react:ons greater among females than among males; but we agree that the reactions are significantly commoner among younger donors.

Effects of Menstruation upon the Incidence of Reactions in Female Donors. - Table III shows the comparative incidence of reactions among female donors of menstrual age who were menstruating and those who were not. The findings relating to each age group are included in the table, as they indicate the progressive fall in reaction rates with increasing age and

TABLE III.-Effect of Menstruation upon the Incidence of Fainting in Females of Menstrual Age

\begin{tabular}{|c|c|c|c|c|c|}
\hline \multirow[b]{2}{*}{ Age } & \multicolumn{2}{|c|}{ Non-menstruating } & \multicolumn{2}{|c|}{ Menstruating } & \multirow[b]{2}{*}{$\begin{array}{l}\text { Diff./S.E. } \\
\text { of Diff. }\end{array}$} \\
\hline & $\begin{array}{c}\text { Calculated } \\
\text { No. }\end{array}$ & Fainted & $\begin{array}{c}\text { Calculated } \\
\text { No. }\end{array}$ & Faínted & \\
\hline $\begin{array}{cl}\text { Under } & 21 \\
, & 21-30 \\
, & 31-40 \\
, & 41-50\end{array}$ & $\begin{array}{l}258 \cdot 73 \\
721 \cdot 63 \\
405 \cdot 67 \\
293 \cdot 16\end{array}$ & $\begin{array}{r}12 \cdot 7 \\
5 \cdot 2 \\
4 \cdot 4 \\
3 \cdot 8\end{array}$ & $\begin{array}{r}40 \cdot 27 \\
112 \cdot 36 \\
130 \cdot 52 \\
54 \cdot 38\end{array}$ & $\begin{array}{r}12.5 \\
11.5 \\
7 \cdot 6 \\
9 \cdot 2\end{array}$ & $\begin{array}{l}0.03 \\
2 \cdot 01 \\
1 \cdot 23 \\
1 \cdot 34\end{array}$ \\
\hline All groups & $1,679 \cdot 19$ & $5 \cdot 96$ & $337 \cdot 53$ & $9 \cdot 7$ & $2 \cdot 14$ \\
\hline
\end{tabular}

the constantly lower incidence among those not menstruating compared with those who are. With the exception of the second age group, however, the statistical significance of each of these pairs of figures is unsatisfactory, owing to the necessarily small number of each group examined. Summing all groups up to the age of 50 , the difference between the percentage incidence of fainting is significant. These results confirm the impression we have formed that donors should not attend during the menstrual periods, especially if the latter cause them any inconvenience. The significance of our findings is in our opinion enhanced by the fact that donors who attend while menstruating are to some extent self-selecting, and presumably only those who feel disposed to do so will attend at such times to give their donations. There is no apparent difference between the reactions experienced by menstruating donors and those of non-menstruating individuals, except in one respect. It occasionally happens that donors who have always been subject to dysmenorrhoea of a colicky nature attend on the day on which their period is due. Such donors are liable, shortly after giving their donation, to experience the sudden onset of menstruation associated with severe uterine colic; which differs from their usual pain in its excruciating intensity. We have come to regard this unpleasant sequel as being possibly ischaemic in origin, a form of " uterine angina." This type of reaction is particularly unfortunate, as its victims are liable to be incapacitated for the remainder of the afternoon.

Relationship of Time Interval since the Last Meal and the Incidence of Reactions. - Table IV shows the incidence of fainting, among males and females respectively, grouped according to the time interval since the last meal. Points of note in these figures are the remarkable similarity in the fainting rates of both sexes among those who have had their last meal between one and five hours before giving their blood, and the low rate among donors who have eaten within the previous hour. Owing to the small number of donors in the

TABLE IV.-Incidence of Fainting in Donors in Relation to Time Interval since Last Meal

\begin{tabular}{|c|c|c|c|c|c|}
\hline \multirow{2}{*}{\multicolumn{2}{|c|}{$\begin{array}{l}\text { Time since } \\
\text { Last Meal }\end{array}$}} & \multicolumn{2}{|c|}{ Males } & \multicolumn{2}{|c|}{ Females } \\
\hline & & $\begin{array}{l}\text { Calculated } \\
\text { No. }\end{array}$ & Fainted & $\begin{array}{c}\text { Calculated } \\
\text { No. }\end{array}$ & Fainted \\
\hline $\begin{array}{l}\text { Under } 1 \mathrm{hr} . \\
1-2 \text { hrs. } \\
2-3 \quad " \\
3-5 \% \\
+5 \Rightarrow\end{array}$ & $\begin{array}{l}\ldots \\
\cdots \\
\ldots \\
\ldots\end{array}$ & $\begin{array}{c}29 \cdot 2 \\
526.78 \\
273.94 \\
114 \cdot 81 \\
91 \cdot 65\end{array}$ & $\begin{array}{l}3 \cdot 42 \\
6 \cdot 2 \\
7 \cdot 3 \\
7 \cdot 8 \\
7 \cdot 63\end{array}$ & $\begin{array}{c}80 \cdot 59 \\
1,395.99 \\
497 \cdot 5 \\
153 \cdot 08 \\
79 \cdot 52\end{array}$ & $\begin{array}{c}3 \cdot 72 \\
6 \cdot 5 \\
7 \cdot 83 \\
7 \cdot 8 \\
10 \cdot 0\end{array}$ \\
\hline
\end{tabular}

latter group, however, the significance of the difference in reaction rates between the two groups is not statistically valid. The ratio of difference/S.E. of difference was 0.8 among the males, 1.3 among the females, and 1.5 among males and females together. We cannot therefore draw any conclusions from these findings, except that a three-hour fast, before giving a donation, has no tendency to increase the liability to faint, and may be of value in that the resulting plasma contains less lipoid material in such circumstances. 
Association between General Appearance and Incidence of Fainting.-Table $\mathrm{V}$ gives the incidence of fainting among donors classified according to sex and according to a rough system of bodily build. This confirms the clinical impression

TABLE V.-Incidence of Fainting in Donors Classified according to General Appearance

\begin{tabular}{|c|c|c|c|c|}
\hline \multirow[b]{2}{*}{ Description } & \multicolumn{2}{|c|}{ Males } & \multicolumn{2}{|c|}{ Females } \\
\hline & $\begin{array}{c}\text { Calculated } \\
\text { No. }\end{array}$ & Fainted & $\begin{array}{l}\text { Calculated } \\
\text { No. }\end{array}$ & Fainted \\
\hline $\begin{array}{l}\text { Tall and thin } \\
\text { Short and stout ... } \\
\text { Tall and stout } \\
\text { Short and thin }\end{array}$ & $\begin{array}{l}354 \cdot 9 \\
68 \cdot 35 \\
141 \cdot 55 \\
139 \cdot 3\end{array}$ & $\begin{array}{c}11 \\
5 \cdot 9 \\
5 \\
13\end{array}$ & $\begin{array}{l}336 \cdot 8 \\
473 \cdot 6 \\
136 \cdot 85 \\
576 \cdot 35\end{array}$ & $\begin{array}{c}13 \\
6 \\
10 \\
7.6\end{array}$ \\
\hline
\end{tabular}

that those of tall thin build were most often associated with a predisposition to vasomotor reactions.

Temperature and Relative Humidity.-No note was made of atmospheric conditions in the buildings at the time of bleeding. Records were, however, obtained of external temperature and relative humidity, but no correlation could be traced between the incidence of fainting and either of these factors. This was contrary to expectation, since the general impression was that reactions were more frequent in hot weather than they were in cold.

Severity of Reactions.-Table VI illustrates the relative incidence of reactions varying in severity. The interpretation of the classification has already been given, Grade 1 being the least and Grade 3 the most severe. Little can be deduced from examination of these results, since there would be a high rate

TABLE VI.-Incidence of Fainting in Donors attending on First, Second, and Subsequent Occasions, with Severity of Reaction in each Case

\begin{tabular}{c|c|c|c|c}
\hline $\begin{array}{c}\text { Grade } \\
\text { of } \\
\text { Faint }\end{array}$ & $\begin{array}{c}\text { First } \\
\text { Attendance }\end{array}$ & $\begin{array}{c}\text { Second } \\
\text { Attendance }\end{array}$ & $\begin{array}{c}\text { Third or } \\
\text { Subsequent } \\
\text { Attendance }\end{array}$ & Total \\
\hline 1 & 97 & 43 & 24 & 164 \\
2 & 28 & 15 & 7 & 50 \\
3 & 5 & 1 & 2 & 8 \\
\hline All grades & 130 & 59 & 33 & 222 \\
\hline
\end{tabular}

of selection among donors who had reacted to previous donations. Conclusions, therefore, cannot be drawn regarding the incidence of fainting among donors who have attended on second or subsequent occasions. Of 59 donors who fainted at their second attendance 26 had done so under similar circumstances before; and of 33 who fainted at their third or subsequent attendance 11 had previously experienced similar reactions. A few cases are on record of donors who suffered their first reaction after their fifth or sixth transfusion.

\section{Summary and Conclusions}

Investigation of syncopal reactions in 3,241 donors, bled over a period of four months, reveals that there is a definite correlation between certain individual and environmental factors and the incidence of these reactions. Factors tending to increase the reaction rate may be classified as follows:

\section{Avoidable}

Environment.-Increased incidence of fainting was observed in circumstances in which supervision of the donors "by the medical officer or senior nursing staff was not adequate. Rest immediately after the donation of blood was also important, as was shown by the low rate of reactions in one hospital where tea was served before the donors moved from their couches.

Isolation.-While it is desirable, for aesthetic reasons, to isolate donors by screens, it is not believed to affect very greatly the tendency to fainting, as donors are reassured by being able to see others giving their blood. "Epidemic" fainting, however, is aggravated under such conditions, and it is better for young donors attending in parties to be separated.

Menstruation.-Donors known to be menstruating should not be accepted, but it is not considered advisable to exclude such donors unless the information is voluntarily given by them.

\section{Unavoidable}

Diathesis.-The incidence of reactions is significantly higher among those of the "asthenic" diathesis than among donors of more stocky appearance. This suggests that syncopal reactions may be associated with increased vagal tone, and this hypothesis is further borne out by certain clinical features of the reactions, such as bradycardia and low blood pressure.

Age.-The higher incidence of fainting among donors under the age of 30 provides further evidence of the association between increased vagal tone and the incidence of syncopal reactions following transfusion.

\section{Treatment}

The usual measures for the treatment of syncope are effective in restoring all cases. No specific drugs, such as atropine, have been used, as, owing to the transient nature of the complaint, such treatment may prove more unpleasant than the reactions themselves. Attention to the above-mentioned environmental factors and avoidance of donors with a tendency to syncopal attacks provide the best prophylactic against unduly high rates of fainting among donors.

My thanks are due to the Director General, Emergency Medical Services, and to Prof. T. B. Davie, for permission to publish the results of this investigation, and to the nursing and secretarial staff of the N.W. Regional Blood Transfusion Service for the large amount of work involved in collecting the material. Grateful acknowledgment is also made to Dr. C. O. Stallybrass for his advice in the interpretation of the figures, and to the Liverpool Observatory and Tidal Institute for information regarding weather conditions.

\section{THE EXPANDING PELVIS}

\section{KATHLEEN VAUGHAN, M.B.}

A fact well known to the ancients was that the pelvis of woman expands during labour. Galen and Soranus both taught that the pelvis gave way at the articulations to let the child's head pass. The members of the Gynaecological Conference held at Amsterdam in 1899 were unanimous in their opinion that the pelvic joints (the symphysis in front and the two sacro-iliac joints at the back) softened in pregnancy, moved apart, and so led to a definite enlargement of the area enclosed by the pelvis during labour. It was claimed that by suitable posture a definite increase of both antero-posterior and transverse diameters could be obtained in every pelvic plane, and it was stated that in the lithotomy position the lengthening of the true conjugate at the brim which could be obtained by posture amounted to 0.5 to $1 \mathrm{~cm}$., while at the outlet the separation of the ischial tuberosities in the lithotomy position was increased by as much as $2 \mathrm{~cm}$. This expansion varied with the individual, being greatest in the young and in those engaged in active work. This is one reason why in countries such as India marriage at puberty is traditional. Experience has shown that where skilled assistance in childbirth is not available, offspring are more likely to be born alive when the pelvis is still flexible.

\section{The Flexibility of the Pelvic Joints}

Ralph Brooke (1934) has found that just before delivery the flexibility of the pelvic joints is $2 \frac{1}{2}$ times as great as in the unimpregnated state. Besides the increase noted at the brim and at the outlet, there is another easily observed increase-namely, the widening of the space between the posterior-superior spines of the ilia. The difference made here between hollowing and rounding of the back is normally half an inch (about $1.25 \mathrm{~cm}$.), but this separation of the spines is increased during pregnancy and by suitable exercise to over $3 \mathrm{~cm}$. I find in practice it gives a very good indication of the flexibility of the individual pelvis.

With the valuable co-operation of Miss K. C. Clark of Ilford Ltd., well known for her original work on positioning, I chose as model a healthy well-grown child dancer of 14 years, as the bones at that age are less dense. The accompanying tracings show two lateral vertical views of her spine and pelvis. The first is on tiptoe with arms above the head to get the maximum hollowing of the back. The second is taken in the squatting position with head bent well down between the knees to ensure the maximum rounding of the back. These studies show that change of posture has more important effects than 